\title{
Appropriateness of colonoscopy in Europe (EPAGE II) Iron-deficiency anemia and hematochezia
}

Authors

Institutions
I. Peytremann-Bridevaux ${ }^{1}$, C. Arditi ${ }^{1}$, F. Froehlich²,3 ${ }^{2}$ J. O’Malley ${ }^{4}$, P. Fairclough ${ }^{5}$, O. Le Moine ${ }^{6}$, R. W. Dubois ${ }^{7}$, J.-J. Gonvers ${ }^{2}$, S. Schusselé Filliettaz ${ }^{1}$, J.-P. Vader ${ }^{1}$, P. Juillerat ${ }^{2}$, V. Pittet ${ }^{1}$, B. Burnand ${ }^{1}$ and the EPAGE II Study Group ${ }^{8}$

Institutions are listed at the end of article. submitted 17 June 2008 accepted after revision 5 December 2008

\section{Bibliography}

DOI $10.1055 / \mathrm{s}-0028-1119644$ Endoscopy 2009; 41:

227-233@ Georg Thieme Verlag KG Stuttgart · New York ISSN 0013-726X

\section{Corresponding author} B. Burnand, MD MPH Healthcare Evaluation Unit Institute of Social and Preventive Medicine (IUMSP) Centre Hospitalier Universitaire Vaudois and University of Lausanne

Rue du Bugnon 17 $\mathrm{CH}-1005$ Lausanne Switzerland Fax: +41-21-3144954 Bernard.Burnand@chuv.ch
Background and study aims: To summarize the published literature on assessment of appropriateness of colonoscopy for the investigation of iron-deficiency anemia (IDA) and hematochezia, and report appropriateness criteria developed by an expert panel, the 2008 European Panel on the Appropriateness of Gastrointestinal Endoscopy, EPAGE II.

Methods: A systematic search of guidelines, systematic reviews and primary studies regarding the evaluation and management of IDA and hematochezia was performed. The RAND/UCLA Appropriateness Method was applied to develop appropriateness criteria for colonoscopy for these conditions.

Results: IDA occurs in $2 \%-5 \%$ of adult men and postmenopausal women. Examination of both the upper and lower gastrointestinal tract is recommended in patients with iron deficiency. Colonoscopy for IDA yields one colorectal cancer (CRC) in every 9-13 colonoscopies. Hematoche-

\section{Introduction}

\section{$\nabla$}

Iron-deficiency anemia (IDA) is a condition where objective iron deficiency is at the origin of the anemia. The World Health Organization (WHO) defines anemia as a hemoglobin value of $<120 \mathrm{~g} / \mathrm{l}$ for nonpregnant women, and < $130 \mathrm{~g} / \mathrm{l}$ for men. IDA is a very common condition, particularly in women. In industrialized countries, it is estimated that $23 \%$ of pregnant women, $10 \%$ of all women (15-59 years), $4 \%$ of men (15-59 years) and $12 \%$ of elderly individuals $\geq 60$ years are anemic [1]. IDA is commonly (62\%) caused by chronic blood loss from the gastrointestinal tract. Peptic ulcerations are the commonest lesions found in the upper gastrointestinal tract, while cancers are one of the most common abnormalities discovered in the colon. Other causes of IDA include cumulative menstrual blood loss or pregnancy in premenopausal women, de- zia is a well-recognized alarm symptom and such patients are likely to be referred for colonoscopy. Colonoscopy is unanimously recommended in patients aged $\geq 50$. Diverticulosis, vascular ectasias, and ischemic colitis are common causes of acute lower gastrointestinal bleeding (LGIB); CRC is found in $0.2 \%-11 \%$ of the colonoscopies performed for LGIB. Most patients with scant hematochezia have an anorectal or a distal source of bleeding. The expert panel considered most clinical indications for colonoscopy as appropriate in the presence of IDA (58\%) or hematochezia ( $83 \%$ ). Conclusion: Despite the limitations of the published studies, guidelines unanimously recommend colonoscopy for the investigation of IDA and hematochezia in patients aged $\geq 50$ years. These indications were also considered appropriate by EPAGE II, as were indications in patients at low risk for CRC with no obvious cause of bleeding found during adequate previous investigations.

creased gastrointestinal absorption (malabsorption syndromes), and chronic intravascular hemolysis, among others.

Lower gastrointestinal bleeding (LGIB) usually refers to blood loss originating from a lesion distal to the ligament of Treitz [2], even though approximately $10 \%$ of patients with hematochezia may have an upper gastrointestinal source of bleeding $[3,4]$. LGIB may manifest itself as hematochezia (rectal bleeding: visible bright red or maroon blood per rectum), as opposed to melena (dark stools), which is most often a manifestation of upper gastrointestinal bleeding. Acute LGIB is of recent duration ( $<3$ days) and may result in hemodynamic instability, rapid hemoglobin decrease and/or the need for blood transfusion [5]. Chronic LGIB corresponds to the passage of blood per rectum over $>3$ days. The patient with chronic bleeding may present with fecal occult blood (IDA and/or positive fecal occult blood test 
[FOBT]), intermittent melena, or scant hematochezia [5].

LGIB is mainly a problem of the elderly that reflects the growing incidence rate of colonic lesions associated with increasing age (e.g. polyps, diverticulosis, colorectal cancer and angiodysplasia) [2]. The prevalence of rectal bleeding (previous 12 months) in the general population may vary between $15 \%$ and $30 \%$ [6,7]. Major causes of LGIB can be divided into the following categories: anatomical (e.g. diverticulosis), vascular (e.g. angiodysplasia, ischemic), inflammatory (e.g. inflammatory bowel disease [IBD], infectious), and neoplastic [8]. The most commonly diagnosed lesions are diverticulosis, angiodysplasia, and hemorrhoids. Other causes include colon polyps, colorectal cancer (CRC), and IBD. The occurrence of polyps, colorectal cancer, and diverticulosis increases with increasing patient age. Since hemorrhoids and diverticula are very common in the general population, it is difficult to relate the episode of bleeding to this type of lesion unless the bleeding site is unequivocally visualized during endoscopy. This is particularly true for young individuals ( $<50$ years) in whom hemorrhoids are a common cause of minor hematochezia. Though LGIB may have multiple causes, the major clinical concern is its association with CRC [9-11].

In April 2008, a multidisciplinary European expert panel, EPAGE II, convened in Montreux, Switzerland, to discuss and develop criteria for the appropriate use of colonoscopy. This article presents the literature review on IDA and hematochezia provided to the panelists before the panel meeting, and also presents the panel's results. It is an update of a previous literature review and consideration of appropriateness criteria published in 1999 $[12,13]$.

The investigation of massive LGIB has not been addressed in this review since this category of patient presents different risk-factor, morbidity and mortality profiles. This review also does not address the investigation of obscure bleeding, melena, and FOBT, these issues being examined separately.

\section{Methods}

$\nabla$

The literature review process included a systematic search of websites issuing guidelines and of Medline (1997-February 2008 ) to select published guidelines, systematic reviews, and primary studies assessing the use of colonoscopy in patients with IDA or hematochezia. The literature published before 1997 is presented in the previous literature review $[12,13]$.

The targeted patients had IDA or hematochezia. Patients with IDA were supposed to have no malabsorption syndrome, were with or without upper or lower abdominal symptoms, were at average or increased risk of CRC, and a potential source of bleeding had or had not been investigated or possibly found. Patients with hematochezia were hemodynamically stable and free of IBD, at average or increased risk of CRC, with or without previous gastrointestinal investigations and possibly an identified source of bleeding; the presence of blood, either bright red or not, was also considered.

The application of the RAND/UCLA Appropriateness Method is described in detail in a companion article in this issue [14]. Briefly, this process is a formal explicit panel method that allows classification of each indication into one of the following categories of appropriateness: inappropriate; uncertain; appropriate; appropriate and necessary (i.e. the indication mandates colonoscopy). To simplify the graphical presentation of the appropriateness results, these four categories were consolidated into two clusters:
"Appropriate" (appropriate, and appropriate and necessary) and "Not appropriate" (inappropriate, and uncertain). In addition to simplification and enhanced clarity of presentation, the rationale for this choice was that in many instances in the case of a non-appropriate scenario, whether it be uncertain or inappropriate, the decision for not proposing the colonoscopy should be specifically discussed and shared with the patient. All clinical indications and their ratings are available on the EPAGE website (www.epage.ch).

\section{Results: Literature review}

$\nabla$

\section{Iron-deficiency anemia}

All 17 primary studies published between January 1997 and February 2008 assessing the use of endoscopy in men and postmenopausal women with IDA were case studies or cross-sectional studies (Table e1)[15-31]. Main endoscopic findings were CRC $(0 \%-34 \%)$, adenomas $(1 \%-27 \%)$, angiodysplasia $(0 \%-7 \%)$ and inflammatory bowel disease $(0.4 \%-10 \%)$ (Table e1). Dual colonic and upper intestinal disease was reported in up to $29 \%$ of the cases [19]. Based on these results, the majority of authors recommend upper and lower endoscopy for the investigation of IDA. If gastroscopy is performed first, most authors recommend colonoscopy regardless of the findings of the upper gastrointestinal endoscopy. Neither the use of nonsteroidal anti-inflammatory drugs (NSAIDs) nor the presence of gastrointestinal symptoms were consistently reported as being associated with abnormalities in the corresponding portion of the gastrointestinal tract. Studies reporting the prevalence of gastrointestinal lesions in persons with low ferritin levels but no anemia showed that gastrointestinal lesions and CRC were found in about $50 \%$ and $5 \%$ of the patients at endoscopy, respectively $[32,33]$. The prevalence of colorectal cancer was higher for iron-deficient anemic, compared with iron-deficient nonanemic, patients [21]. In addition, ferritin levels of below $100 \mathrm{ng} / \mathrm{mL}$ were shown to be associated with an increased risk of CRC in anemic patients compared with those who were nonanemic [34].

In young women, excessive menstrual blood loss is generally considered to be the main cause of IDA. The diagnostic yield of endoscopy in premenopausal women with IDA was examined in 7 studies (Table e2) [24,35-40]. Concomitant upper and lower gastrointestinal lesions, including gastrointestinal malignancies, were discovered at a prevalence rate considered high enough to recommend bidirectional endoscopy for premenopausal women with IDA, particularly in those $>40$ years of age. However, gastrointestinal malignancy is rarely encountered in premenopausal women in the general population and indeed, in one US population-based cohort study, it was reported that none of the premenopausal women, with or without IDA, were diagnosed with gastrointestinal malignancy within 2 years of hemoglobin and iron measurement [41].

Authors of British and American guidelines generally advocate performing colonoscopy and upper endoscopy in men and women with IDA [42-45]. Special consideration regarding premenopausal women and young men is given only by the British Society of Gastroenterology (BSG). The latter recommends both upper and lower endoscopy for asymptomatic premenopausal women with IDA aged $\geq 50$ years, despite little existing data to support this. For women aged $<50$ years, the BSG suggests performance of colonoscopy in the presence of colonic symptoms, a strong family history of $\mathrm{CRC}$, or persistent IDA following iron supplementation and correction of potential causes of loss [44]. Young 
Table 4 Definition of terms used to characterize clinical indications for the use of colonoscopy in patients with iron-deficiency anemia (IDA) or hematochezia.

\begin{tabular}{|c|c|c|}
\hline & Term & Definition \\
\hline \multirow[t]{10}{*}{$\begin{array}{l}\text { Iron-deficiency } \\
\text { anemia }\end{array}$} & $\begin{array}{l}\text { Iron-deficiency anemia (IDA) (malabsorption } \\
\text { symptoms excluded) }\end{array}$ & $\begin{array}{l}\mathrm{Hb}<120 \mathrm{~g} / \mathrm{l} \text { in females or } \mathrm{Hb}<140 \mathrm{~g} / \mathrm{l} \text { in males with no obvious cause of blood } \\
\text { loss, decreased serum iron, decreased ferritin }\end{array}$ \\
\hline & Risk factors for colorectal cancer & $\begin{array}{l}\text { Personal history of colorectal cancer (CRC) or colorectal adenomas, inflam- } \\
\text { matory bowel disease } \\
\text { Or: } \\
\text { Family history of a first-degree relative with CRC or colorectal adenomas, fa- } \\
\text { milial polyposis syndrome, hereditary nonpolyposis colorectal cancer } \\
\text { (HNPCC) syndrome }\end{array}$ \\
\hline & Lower abdominal symptoms & $\begin{array}{l}\text { One or more of the following: } \\
\text { Abdominal pain or discomfort below the umbilicus, change in bowel habits, } \\
\text { bloating }\end{array}$ \\
\hline & Upper abdominal symptoms & $\begin{array}{l}\text { One or more of the following: } \\
\text { Upper abdominal discomfort, dyspepsia, heartburn, early satiety, anorexia, } \\
\text { nausea or vomiting }\end{array}$ \\
\hline & Source of IDA & $\begin{array}{l}\text { Potential lower gastrointestinal bleeding source: } \\
\text { Bleeding diverticula, vascular malformation (AVM), polyp, tumor, colitis di- } \\
\text { agnosed by barium enema, sigmoidoscopy or colonoscopy within the pre- } \\
\text { vious } 3 \text { months. } \\
\text { Potential upper gastrointestinal bleeding source: } \\
\text { Duodenal, gastric or esophageal ulcer, esophageal varices, esophagitis, he- } \\
\text { morrhagic gastritis, erosive gastritis, Mallory-Weiss tear, Dieulafoy lesion } \\
\text { within the previous } 3 \text { months. }\end{array}$ \\
\hline & Lower gastrointestinal investigations* & $\begin{array}{l}\text { Sigmoidoscopy or barium enema since onset of lower abdominal pain or } \\
\text { within past } 5 \text { years }\end{array}$ \\
\hline & Barium enema* & Double-contrast technique \\
\hline & Sigmoidoscopy* & Flexible tube $(60 \mathrm{~cm})$ \\
\hline & Gynecological cause excluded & $\begin{array}{l}\text { No excessive menstrual blood loss } \\
\text { Gynecological examination normal or status after hysterectomy }\end{array}$ \\
\hline & Chronic lower gastrointestinal bleeding & Continuous or intermittent hematochezia or melena of $>3$ days' duration \\
\hline \multirow[t]{7}{*}{ Hematochezia } & Hematochezia & Passage of bright red or maroon blood from the rectum \\
\hline & Hemodynamically stable patient & $\begin{array}{l}\text { No postural hypotension, no fall in blood pressure by more than } 15 \text { - } \\
20 \mathrm{~mm} \mathrm{Hg} \text { when patient sits up. }\end{array}$ \\
\hline & Risk factors for colorectal cancer & $\begin{array}{l}\text { Personal history of colorectal cancer (CRC) or colorectal adenomas, inflam- } \\
\text { matory bowel disease } \\
\text { Or: } \\
\text { Family history of a first-degree relative with CRC or colorectal adenomas, fa- } \\
\text { milial polyposis syndrome, hereditary nonpolyposis colorectal cancer syn- } \\
\text { drome (HNPCC) }\end{array}$ \\
\hline & $\begin{array}{l}\text { Lower gastrointestinal investigations for this } \\
\text { episode }\end{array}$ & Sigmoidoscopy or barium enema \\
\hline & Barium enema & Double-contrast technique \\
\hline & Sigmoidoscopy & Flexible tube $(60 \mathrm{~cm})$ \\
\hline & Potential lower gastrointestinal bleeding source & $\begin{array}{l}\text { Hemorrhoids, fissure, bleeding diverticula, vascular malformation (AVM), } \\
\text { polyp, tumor, colitis diagnosed by barium enema, sigmoidoscopy or colo- } \\
\text { noscopy within the last } 3 \text { months }\end{array}$ \\
\hline
\end{tabular}

\footnotetext{
* For this episode of IDA
}

men with IDA should be investigated in the same way as for older men[44].

\section{Hematochezia}

The diagnostic yield of colonoscopy in LGIB was assessed in 17 primary studies published between 1997 and February 2008 (Table e3) [46-62]. Hemorrhoids (and anal fissures) are the most commonly found lesions in patients presenting with recurrent LGIB. The association between the presence of hemorrhoids and other significant lesions is unclear; even though the presence of anal disease did not exclude the presence of significant colonic lesions [62], others found no association between the presence of anal lesions and diagnosis of neoplasm in young patients [54]. Cancer was found in $0.2 \%-11 \%$ of the colonoscopies performed for lower gastrointestinal bleeding. Polyps were found in $2 \%-$ $21 \%$, angiodysplasia in $1 \%-5 \%$, and inflammatory bowel disease in $2 \%-21 \%$ of the patients. Finally, even if results were sometimes stratified according to age $[49,51,55,57]$, only three studies specifically targeted patients $<50$ years $[54,59,62]$; although rare overall, cancers and other significant proximal lesions were also found in young patients $[49,55,57-60]$.

The American Society of Gastrointestinal Endoscopy (ASGE) recommends colonoscopy for patients aged $>50$ years with scant hematochezia. In young healthy patients ( $\leq 40$ years of age), after an initial evaluation including a digital rectal examination and sigmoidoscopy with or without anoscopy, colonoscopy is generally not considered necessary if a convincing benign source of bleeding (hemorroids, anal fissures) is found[5]. In cases of isolated rectal bleeding, French guidelines (ANAES) recommend complete colonoscopy for patients aged $\geq 50$ years, but do not favor colonoscopy rather than sigmoidoscopy for those aged $<50$ years [63]. However, colonoscopy is recommended by the ANAES 


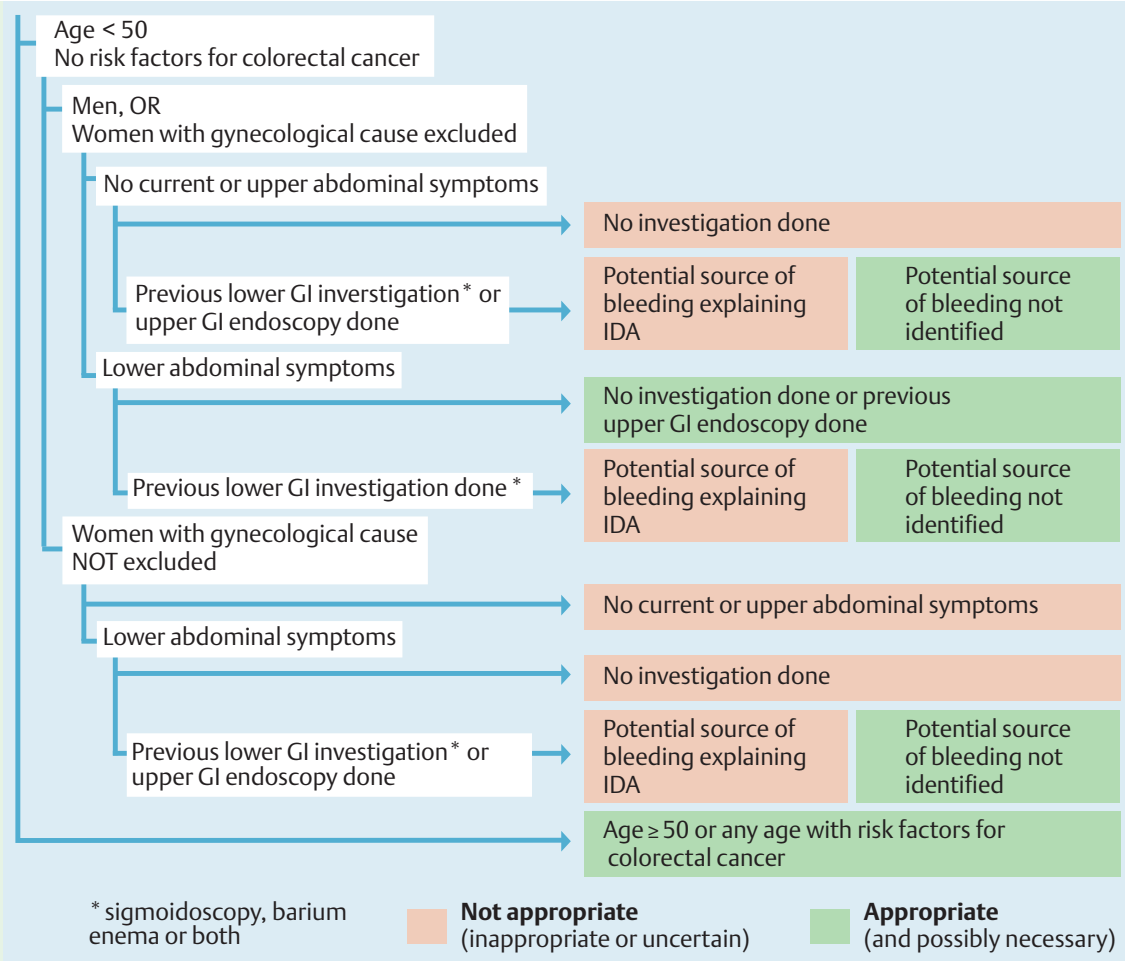

Fig. 1 a Appropriateness ratings of clinical indications for performing colonoscopy in patients with iron-deficiency anemia (IDA) (simplified decision tree). GI, gastrointestinal. Copyright ( 2008 IUMSP/ CHUV, Lausanne, Switzerland - EPAGE II. guidelines irrespective of the patient's age when there are chronic repeated episodes of rectal bleeding [63]. Using a modified Delphi technique, the American College of Radiology developed appropriateness criteria for the treatment of acute nonvariceal gastrointestinal tract bleeding. Colonoscopy was rated appropriate in the case of active bleeding with hematochezia or melena in hemodynamically stable patients [64].

\section{EPAGE II appropriateness criteria}

Out of 463 indications, 48 pertained to IDA and 54 to hematochezia. Terms used for the definition of these scenarios are listed in - Table 4. The proportions of indications related to IDA considered to be appropriate, uncertain, or inappropriate, were $58 \%$, $27 \%$, and $15 \%$, respectively; disagreement between panelists occurred for 19\%. Half of the 28 appropriate IDA indications were deemed necessary (mandating colonoscopy) by the panel. In the presence of hematochezia, most of the indications were considered appropriate (83\%), whereas $13 \%$ and $4 \%$ were rated uncertain and inappropriate, respectively; the degree of disagreement was average (9\%), and most of the appropriate indications were judged necessary ( $87 \%)$.

For IDA, $\odot$ Fig. 1 a shows the color-coded panel results as a simplified dichotomy: "Not appropriate" (inappropriate, or uncertain), versus "Appropriate" (appropriate and possibly necessary). Terms used for the definition of these scenarios are listed in - Table 4. The intentionally simplified version shown in $\bullet$ Fig. $\mathbf{1 a}$ mainly reveals that colonoscopy is appropriate, and for some situations even necessary, in patients $\geq 50$ years with IDA, in women without gynecological reasons for IDA, and in men $<50$ years with lower abdominal symptoms without prior gastrointestinal investigations, or with prior investigations which did not reveal the origin of IDA.

Fig. e1b is a more detailed color-coded presentation of appropriateness results for IDA scenarios. In patients aged $\geq 50$ years all indications were appropriate, and even necessary when a potential bleeding source had not been identified. In women $<50$ years, for whom a possible gynecological cause of anemia was not excluded, all scenarios were considered inappropriate or uncertain, unless previous upper gastrointestinal endoscopy or flexible sigmoidoscopy had failed to reveal a potential source of bleeding in the presence of lower abdominal symptoms. In men $<50$ years and women $<50$ years in whom a gynecological cause had already been excluded, colonoscopy was deemed appropriate in the presence of lower abdominal symptoms in most scenarios, whereas in the absence of lower abdominal symptoms, all scenarios were inappropriate or uncertain, unless a potential source of bleeding had not been revealed by prior gastrointestinal investigations.

For hematochezia, $\bullet$ Fig. 2 a shows the color-coded panel results as a simplified dichotomy: "Not appropriate" (inappropriate or uncertain), versus "Appropriate" (appropriate and possibly necessary). In patients $\geq 50$ years, colonoscopy was deemed appropriate in almost all scenarios. In patients $<50$ years, colonoscopy was appropriate in the presence of any risk factors for CRC, as well as in average-risk patients without bright red-blood hematochezia who had never undergone investigation, or in the case of normal flexible sigmoidoscopy.

Fig. e2b shows detailed appropriateness criteria in hematochezia. Above age 50, and in the presence of any risk factor for CRC, almost all scenarios were considered appropriate and necessary. In patients aged $<50$ at average risk of colorectal cancer, colonoscopy was considered appropriate if a previous anoscopy or sigmoidoscopy did not reveal a potential source of bleeding, and as the first-line lower gastrointestinal investigation in the absence of bright red blood. In patients $<50$ years with any risk factor for CRC, colonoscopy was considered appropriate in almost all situations. 


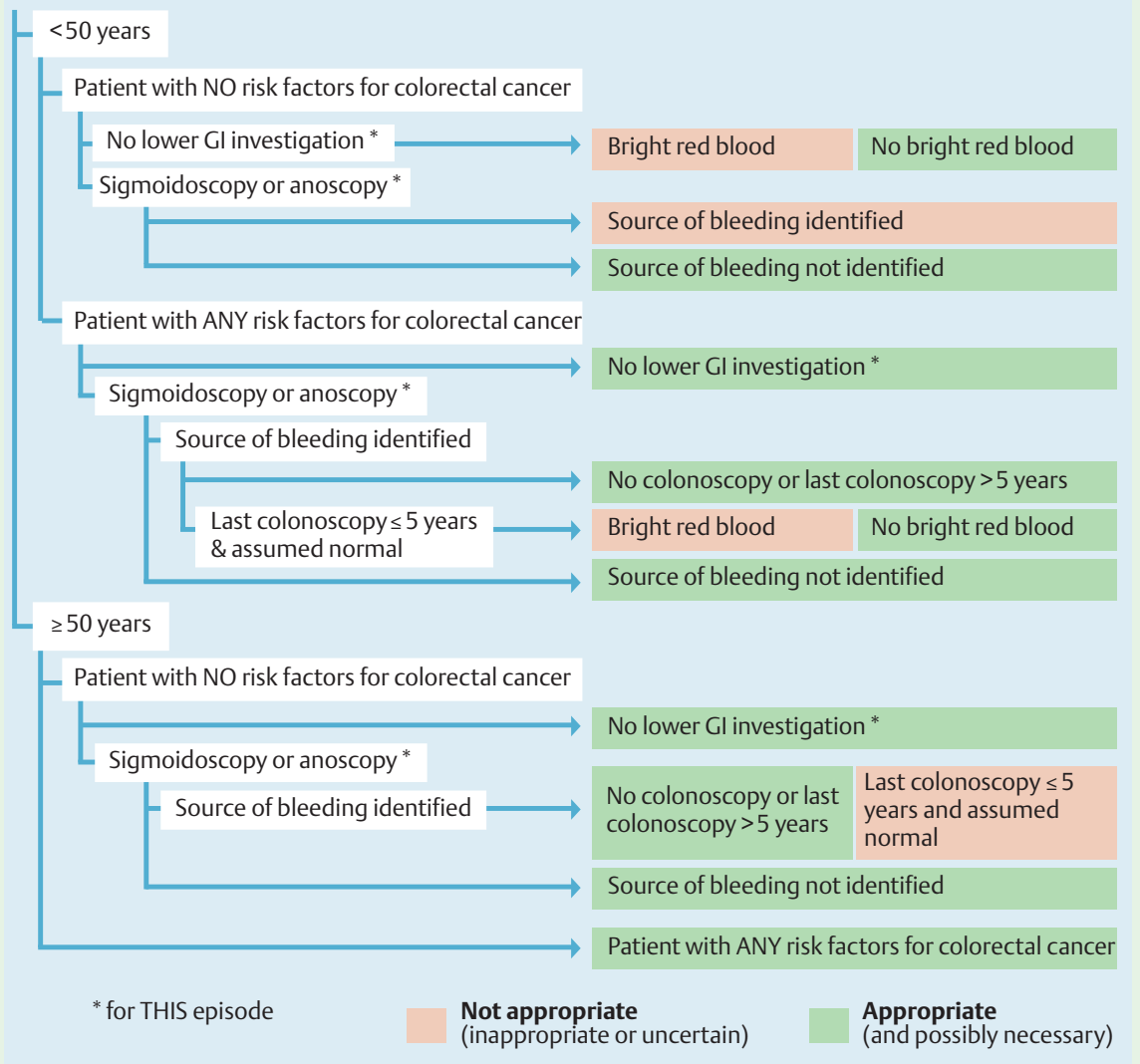

Fig. 2a Appropriateness ratings of clinical indications for performing colonoscopy in patients with hematochezia (simplified decision tree). Gl, gastrointestinal. Copyright ( 2008 IUMSP/CHUV, Lausanne, Switzerland - EPAGE II.

\section{Conclusions}

Most of the published studies have limitations: some studies lacked a control group, which made it impossible to determine whether comparable lesions would have been detected in individuals with similar characteristics but without IDA or hematochezia; indeed, the vast majority of studies included are only case series; furthermore, selection bias may have occurred because individuals were mainly referred to specialized tertiary centers, which may have resulted in the selection of individuals with IDA or hematochezia who were sicker than those in the general population; and in addition, study populations were small. Conclusions are also limited by heterogeneity in the definition of anemia, patient inclusion and exclusion criteria (study population), the investigations performed, and the degree to which lesions are considered to be a potential cause of IDA or hematochezia. In addition, some authors also reported gastrointestinal lesions which were not responsible for IDA or hematochezia. Direct comparison of results between these studies is therefore difficult, and in consequence guidelines and recommendations based on these studies should be interpreted with caution.

This review of the literature highlights the fact that despite the modest quality of evidence, colonoscopy is recommended in the investigation of almost all cases of IDA and hematochezia. It remains unclear, however, in patients $<50$ years, whether the proportion of high-risk adenomas and cancers is high enough to systematically recommend the performance of colonoscopy, particularly in patients with hematochezia. A rigorous assessment of the appropriateness of colonoscopy in cases of IDA and hematochezia is needed, especially in young persons, as well as in cases where previously performed investigations identified a potential source of bleeding.
In summary. and in accordance with the literature review and clinical practice guidelines, the expert panel considered that IDA and hematochezia are undisputed indications for colonoscopy in patients aged $>50$ years. In patients at lower risk of colorectal cancer (CRC), colonoscopy was in general only considered appropriate once potential sources of bleeding have been excluded by adequate gastrointestinal and nongastrointestinal investigations. In young patients ( $<40$ years) with hematochezia, colonoscopy would probably not be recommended as the first-step investigation.

\section{Acknowledgments \\ $\nabla$}

The authors gratefully acknowledge the selfless commitment and invaluable contribution of the expert panel members, who made this project possible: Lars Agréus (SE), Christoph Beglinger $(\mathrm{CH})$, Peter Bytzer (DK), Michel Delvaux (FR), Volker F. Eckardt (DE), Peter D. Fairclough (UK), François Lacaine (FR), Olivier Le Moine (BE), Vicente Lorenzo Zúñiga Garcia (ES), Giorgio Minoli (IT), Mattijs E. Numans (NL), Daniel Oertli (CH), John O'Malley (UK), Alastair Windsor (UK). The authors warmly thank Susan Giddons for her invaluable assistance in the administration of the expert panel process, as well as in the meticulous preparation of the manuscripts.

This work was supported by a grant from the Loterie Romande (Switzerland).

\section{Competing interests: None}




\section{Appendix: The EPAGE II Study Group}

See page 205 .

\section{Institutions}

Healthcare Evaluation Unit, Institute of Social and Preventive Medicine (IUMSP), Centre Hospitalier Universitaire Vaudois and University of Lausanne, Lausanne, Switzerland

2 Department of Gastroenterology and Hepatology, Centre Hospitalier Universitaire Vaudois and University of Lausanne, Lausanne, Switzerland

3 Department of Gastroenterology, University of Basle, Basle, Switzerland

${ }^{4}$ General Practitioner, Moreton, United Kingdom

Endoscopy Unit, Barts and The London NHS Trust, London, United Kingdom

${ }^{6}$ Gastroenterology Department, Hôpital Erasme-ULB, Brussels, Belgium

7 Cerner LifeSciences, Beverly Hills, USA

The EPAGE II Study Group*

\section{References}

1 WHO. Iron deficiency anemia. Assessment, prevention, and control. A guide for programme managers. 2001. Available at: http://www. who.int/nutrition/publications/anaemia_iron_pub/en/index.html (Accessed 11 Feb 2009)

2 Zuckerman GR, Prakash C. Acute lower intestinal bleeding: part I: clinical presentation and diagnosis. Gastrointest Endosc 1998; 48: 606617

3 Byers SE, Chudnofsky CR, Sorondo B et al. Incidence of occult upper gastrointestinal bleeding in patients presenting to the ED with hematochezia. Am J Emerg Med 2007; 25: 340-344

4 Jensen DM, Machicado GA. Diagnosis and treatment of severe hematochezia. The role of urgent colonoscopy after purge. Gastroenterology 1988: 95: 1569 - 1574

5 Davila RE, Rajan E, Adler DG et al. ASGE Guideline: the role of endoscopy in the patient with lower-gastrointestinal bleeding. Gastrointest Endosc 2005; 62: 656-660

6 Fijten GH, Blijham GH, Knottnerus JA. Occurrence and clinical significance of overt blood loss per rectum in the general population and in medical practice. Br J Gen Pract 1994; 44: 320 - 325

7 Talley NJ, Jones M. Self-reported rectal bleeding in a United States community: prevalence, risk factors, and health care seeking. Am J Gastroenterol 1998; 93: 2179-2183

$8 \mathrm{Lim} \mathrm{JK}$, Ahmed A. Endoscopic approach to the treatment of gastrointestinal bleeding. Tech Vasc Intervent Radiol 2004; 7: $123-129$

9 Hamilton W, Round A, Sharp D, Peters TJ. Clinical features of colorectal cancer before diagnosis: a population-based case-control study. $\mathrm{Br} \mathrm{J}$ Cancer 2005; 93: 399-405

10 Helfand M, Marton KI, Zimmer-Gembeck MJ et al. History of visible rectal bleeding in a primary care population. Initial assessment and 10year follow-up. JAMA 1997; 277: 44-48

11 Jones R, Latinovic R, Charlton J, Gulliford MC. Alarm symptoms in early diagnosis of cancer in primary care: cohort study using General Practice Research Database. BMJ 2007; 334: 1040

12 De Bosset V, Gonvers JJ, Burnand B et al. 7. Appropriateness of colonoscopy: iron-deficiency anemia. Endoscopy 1999; 31: 627-630

13 Gonvers JJ, De Bosset V, Froehlich F et al. 8. Appropriateness of colonoscopy: hematochezia. Endoscopy 1999; 31: 631 -636

14 Juillerat P, Peytremann-Bridevaux I, Vader JP et al. Appropriateness of colonoscopy in Europe (EPAGE II) Presentation of methodology, general results, and analysis of complications. Endoscopy 2008; 41: 240246

15 Annibale B, Capurso G, Chistolini A et al. Gastrointestinal causes of refractory iron deficiency anemia in patients without gastrointestinal symptoms. Am J Med 2001; 111: 439-445

16 Capurso G, Baccini F, Osborn J et al. Can patient characteristics predict the outcome of endoscopic evaluation of iron deficiency anemia: a multiple logistic regression analysis. Gastrointest Endosc 2004; 59: $766-771$

17 Coban E, Timuragaoglu A, Meric M. Iron deficiency anemia in the elderly: prevalence and endoscopic evaluation of the gastrointestinal tract in outpatients. Acta Haematol 2003; 110: $25-28$
18 Fireman Z, Gurevich V, Coscas D et al. Results of gastrointestinal evaluation in 90 hospitalized iron deficiency anemia patients. Isr Med Assoc J 1999; 1: $232-235$

19 Hardwick RH, Armstrong CP. Synchronous upper and lower gastrointestinal endoscopy is an effective method of investigating iron-deficiency anaemia. Br J Surg 1997; 84: 1725-1728

20 James MW, Chen CM, Goddard WP et al. Risk factors for gastrointestinal malignancy in patients with iron-deficiency anaemia. Eur J Gastroenterol Hepatol 2005; 17: 1197-1203

21 Joosten E, Ghesquiere B, Linthoudt H et al. Upper and lower gastrointestinal evaluation of elderly inpatients who are iron deficient. Am J Med 1999; 107: $24-29$

22 Lindsay JO, Robinson SD, Jackson JE, Walters JR. The investigation of iron deficiency anemia - a hospital based audit. Hepatogastroenterology 1999; 46: $2887-2890$

23 Nahon S, Lahmek P, Aras N et al. Management and predictors of early mortality in elderly patients with iron deficiency anemia: a prospective study of 111 patients. Gastroenterol Clin Biol 2007; 31: 169-174

24 Nahon S, Lahmek P, Lesgourgues B et al. Predictive factors of gastrointestinal lesions in 241 women with iron deficiency anemia. Am J Gastroenterol 2002; 97: 590-593

25 Niv E, Elis A, Zissin R et al. Iron deficiency anemia in patients without gastrointestinal symptoms - a prospective study. Fam Pract 2005; 22: $58-61$

26 Reyes LA, Gomez CF, Galvez CC, Mino FG. Iron-deficiency anemia due to chronic gastrointestinal bleeding. Rev Esp Enferm Dig 1999; 91: $345-$ 358

27 Sari R, Aydogdu I, Sevinc A, Karincaoglu M. Upper and lower gastrointestinal endoscopical investigation in elderly patients with iron deficiency anaemia. Haematologia (Budapest) 2002; 31: 327-332

28 Schizas AM, Reid R, George ML. Can haematological indices predict positive findings at endoscopy in anaemic patients? Ann R Coll Surg Engl 2007; 89: 221 - 225

29 Stephens MR, Hopper AN, White SR et al. Colonoscopy first for iron-deficiency anaemia: a numbers needed to investigate approach. QJM 2006; 99: 389- 395

30 Till SH, Grundman MJ. Prevalence of concomitant disease in patients with iron deficiency anaemia. BMJ 1997; 314: 206-208

31 Wang SA, Fadare O, Nagar A et al. Gastrointestinal endoscopic findings in men with unexplained anemia and low normal ferritin values. Am J Hematol 2006; 81: $324-327$

32 Lee JG, Sahagun G, Oehlke MA, Lieberman DA. Serious gastrointestinal pathology found in patients with serum ferritin values < or $=50 \mathrm{ng}$ / ml. Am J Gastroenterol 1998; 93: 772 - 776

33 Wilcox CM, Alexander LN, Clark WS. Prospective evaluation of the gastrointestinal tract in patients with iron deficiency and no systemic or gastrointestinal symptoms or signs. Am J Med 1997; 103: 405-409

34 Sawhney MS, Lipato T, Nelson DB et al. Should patients with anemia and low normal or normal serum ferritin undergo colonoscopy? Am J Gastroenterol 2007; 102: $82-88$

35 Annibale B, Lahner E, Chistolini A et al. Endoscopic evaluation of the upper gastrointestinal tract is worthwhile in premenopausal women with iron-deficiency anaemia irrespective of menstrual flow. Scand J Gastroenterol 2003; 38: 239-245

36 Bini EJ, Micale PL, Weinshel EH. Evaluation of the gastrointestinal tract in premenopausal women with iron deficiency anemia. Am J Med 1998; 105: $281-286$

37 Fireman Z, Zachlka R, Abu MS, Kopelman Y. The role of endoscopy in the evaluation of iron deficiency anemia in premenopausal women. Isr Med Assoc J 2006; 8: 88-90

38 Green BT, Rockey DC. Gastrointestinal endoscopic evaluation of premenopausal women with iron deficiency anemia. J Clin Gastroenterol 2004; 38: 104-109

39 Kepczyk T, Cremins JE, Long BD et al. A prospective, multidisciplinary evaluation of premenopausal women with iron-deficiency anemia. Am J Gastroenterol 1999; 94: 109-115

40 Park DI, Ryu SH, Oh SJ et al. Significance of endoscopy in asymptomatic premenopausal women with iron deficiency anemia. Dig Dis Sci 2006; 51: $2372-2376$

41 Ioannou GN, Rockey DC, Bryson CL, Weiss NS. Iron deficiency and gastrointestinal malignancy: a population-based cohort study. Am J Med 2002; 113: $276-280$

42 American Gastroenterological Association medical position statement: evaluation and management of occult and obscure gastrointestinal bleeding. Gastroenterology 2000; 118: 197-201 
43 Appropriate use of gastrointestinal endoscopy. A consensus statement from the American Society for Gastrointestinal Endoscopy. Gastrointest Endosc 2000; 52: 831-837

44 Goddard AF, James MW, McIntyre AS, Scott BB on behalf of the BSG. Guidelines for the management of iron deficiency anemia. 2005 Available at: http://www.bsg.org.uk/pdf word_does/iron_def.pdf (Accessed 11 Feb 2009)

45 Zuckerman GR, Prakash C, Askin MP, Lewis BS. AGA technical review on the evaluation and management of occult and obscure gastrointestinal bleeding. Gastroenterology 2000; 118: $201-221$

46 Adler A, Roll S, Marowski B et al. Appropriateness of colonoscopy in the era of colorectal cancer screening: a prospective, multicenter study in a private-practice setting (Berlin Colonoscopy Project 1, BECOP 1). Dis Colon Rectum 2007; 50: 1628 - 1638

47 Al-Shamali MA, Kalaoui M, Hasan F et al. Colonoscopy: evaluating indications and diagnostic yield. Ann Saudi Med 2001; 21: 304-307

$48 \mathrm{du}$ Toit J, Hamilton W, Barraclough K. Risk in primary care of colorectal cancer from new onset rectal bleeding: 10 year prospective study. BMJ 2006; 333: 69-70

49 Eckardt VF, Schmitt T, Kanzler G et al. Does scant hematochezia necessitate the performance of total colonoscopy? Endoscopy 2002; 34: 599603

50 Exbrayat C, Garnier A, Billette DV et al. [Yield of colonoscopy by indication and consequences for colorectal polyp and cancer screening: a prospective survey in Isere, France]. Gastroenterol Clin Biol 2002; 26: $225-230$

51 Fine KD, Nelson AC, Ellington RT, Mossburg A. Comparison of the color of fecal blood with the anatomical location of gastrointestinal bleeding lesions: potential misdiagnosis using only flexible sigmoidoscopy for bright red blood per rectum. Am J Gastroenterol 1999; 94: 3202 - 3210

52 Gonvers JJ, Harris JK, Wietlisbach $V$ et al. A European view of diagnostic yield and appropriateness of colonoscopy. Hepatogastroenterology 2007; 54: 729-735

53 Lasson A, Kilander A, Stotzer PO. Diagnostic yield of colonoscopy based on symptoms. Scand J Gastroenterol 2008; 43: 356-362

54 Lewis JD, Shih CE, Blecker D. Endoscopy for hematochezia in patients under 50 years of age. Dig Dis Sci 2001; 46: 2660-2665

55 Mulcahy HE, Patel RS, Postic G et al. Yield of colonoscopy in patients with nonacute rectal bleeding: a multicenter database study of 1766 patients. Am J Gastroenterol 2002; 97: 328 - 333

56 Puglisi C, Russo F, Barbera C et al. Colonoscopic evaluation of hematochezia in low and average risk patients for colorectal cancer: A prospective study. World J Gastroenterol 2006; 12: 7304 - 7308

57 Schmulewitz N, Fisher DA, Rockey DC. Early colonoscopy for acute lower gastrointestinal bleeding predicts shorter hospital stay: a retrospec- tive study of experience in a single center. Gastrointest Endosc 2003; 58: $841-846$

58 Segal WN, Greenberg PD, Rockey DC et al. The outpatient evaluation of hematochezia. Am J Gastroenterol 1998; 93: 179-182

59 Spinzi G, Fante MD, Masci E et al. Lack of colonic neoplastic lesions in patients under $50 \mathrm{yr}$ of age with hematochezia: a multicenter prospective study. Am J Gastroenterol 2007; 102: 2011 - 2015

60 Van Rosendaal GM, Sutherland LR, Verhoef MJ et al. Defining the role of fiberoptic sigmoidoscopy in the investigation of patients presenting with bright red rectal bleeding. Am J Gastroenterol 2000; 95: 11841187

61 Wilcox CM, Clark WS. Causes and outcome of upper and lower gastrointestinal bleeding: the Grady Hospital experience. South Med J 1999; 92: $44-50$

62 Wong RF, Khosla R, Moore JH, Kuwada SK. Consider colonoscopy for young patients with hematochezia. J Fam Pract 2004; 53: 879-884

63 ANAES (French National Agency for Accreditation and Evaluation in Healthcare). Indications for lower gastrointestinal endoscopy (excluding population screening). 2004 Available at: http://www.bassante.fr portal jems/e_272348 endoscopie-digestive-basse-indications-en-dehors-du-depistage-en-population (Accessed 11 Feb 2009)

64 Millward SF, Bakal CW, Weintraub JL et al. Treatment of acute nonvariceal gastrointestinal tract bleeding. 2006 Available at: http://www. guidelines.gov/summary/summary.aspx?doc_id=10595 (Accessed 24 Feb 2009)

The following figures and tables are available online: www.thieme-connect.com/media/endoscopy/200903/supmat/ endo846.pdf

Fig. e1b Appropriateness ratings of clinical indications for performing colonoscopy in patients with iron-deficiency anemia (IDA), with malabsorption syndrome excluded (full decision tree). GI, gastrointestinal.

Fig. e2b Appropriateness ratings of clinical indications for performing colonoscopy in patients with hematochezia (without inflammatory bowel disease [IBD]), and who are hemodynamically stable (full decision tree). GI, gastrointestinal.

Table e1 Studies assessing the use of endoscopy for the diagnostic work-up of iron deficiency anemia (IDA), in men and postmenopausal women.

Table e2 Studies assessing the use of endoscopy for the diagnostic work-up of iron-deficiency anemia (IDA), in premenopausal women. Table e3 Studies assessing the use of colonoscopy for the diagnostic work-up of hematochezia. 